\title{
Mortality Risks in New-Onset Childhood Epilepsy
}

\section{ras}

WHAT'S KNOWN ON THIS SUBJECT: Seizure-related death, including sudden death, is a frightening prospect. In part because risk and prevention are poorly understood, neurologists tend to avoid discussions of sudden death with families and young patients.

WHAT THIS STUDY ADDS: Most deaths in children with epilepsy are not seizure related. Relative to the population, however, sudden and seizure-related deaths alone double overall mortality. In uncomplicated epilepsy, such deaths occur at rates comparable to individual leading causes of death in young people.
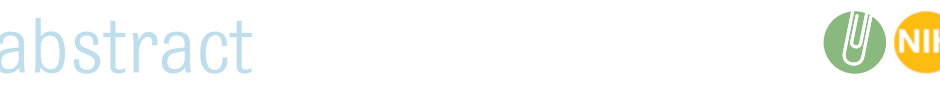

OBJECTIVES: Estimate the causes and risk of death, specifically seizure related, in children followed from onset of epilepsy and to contrast the risk of seizure-related death with other common causes of death in the population.

METHODS: Mortality experiences from 4 pediatric cohorts of newly diagnosed patients were combined. Causes of death were classified as seizure related (including sudden unexpected death [SUDEP]), natural causes, nonnatural causes, and unknown.

RESULTS: Of 2239 subjects followed up for $>30000$ person-years, 79 died. Ten subjects with lethal neurometabolic conditions were ultimately excluded. The overall death rate (per 100000 person-years) was 228; 743 in complicated epilepsy (with associated neurodisability or underlying brain condition) and 36 in uncomplicated epilepsy. Thirteen deaths were seizure-related (10 SUDEP, 3 other), accounting for $19 \%$ of all deaths. Seizure-related death rates were 43 overall, 122 for complicated epilepsy, and 14 for uncomplicated epilepsy. Death rates from other natural causes were 159,561, and 9, respectively. Of 48 deaths from other natural causes, 37 were due to pneumonia or other respiratory complications.

CONCLUSIONS: Most excess death in young people with epilepsy is not seizure-related. Mortality is significantly higher compared with the general population in children with complicated epilepsy but not uncomplicated epilepsy. The SUDEP rate was similar to or higher than sudden infant death syndrome rates. In uncomplicated epilepsy, sudden and seizure-related death rates were similar to or higher than rates for other common causes of death in young people (eg, accidents, suicides, homicides). Relating the risk of death in epilepsy to familiar risks may facilitate discussions of seizurerelated mortality with patients and families. Pediatrics 2013;132:124-131
AUTHORS: Anne T. Berg, PhD, ${ }^{a}$ Katherine Nickels, MD, ${ }^{b}$ Elaine C. Wirrell, MD, ${ }^{b}$ Ada T. Geerts, PhD, ${ }^{c}$ Petra M.C. Callenbach, PhD, ${ }^{\mathrm{d}}$ Willem F. Arts, MD, PhD, ${ }^{\mathrm{c}}$ Christina Rios, BA, ${ }^{e}$ Peter R. Camfield, MD, ${ }^{f}$ and Carol S. Camfield, MD ${ }^{f}$

aEpilepsy Center, Ann \& Robert H. Lurie Children's Hospital of Chicago, Chicago, Illinois; ${ }^{b}$ Epilepsy and Child and Adolescent Neurology, Mayo Clinic, Rochester, Minnesota; 'Neurology, Erasmus Medical Center, Rotterdam, Netherlands; ${ }^{d}$ Neurology, University Medical Center Groningen, University of Groningen,

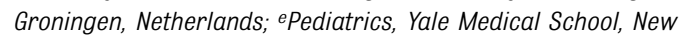
Haven, Connecticut; and Pediatrics, Dalhousie University, Halifax, Nova Scotia, Canada

KEY WORDS

children, epilepsy, mortality, SUDEP

\section{ABBREVIATIONS}

$\mathrm{Cl}$-confidence interval

PY—person-years

SIDS—-sudden infant death syndrome

SUDEP_-sudden unexpected death in epilepsy

Dr Berg is principal investigator for the Connecticut Study of Epilepsy, planned and conducted the pooled analysis, and drafted the initial manuscript; Dr Nickels is the lead author on the Rochester study, provided follow-up time and characterized patient deaths and seizure outcomes, and participated in revising the manuscript; Dr Wirrell is the senior investigator of the Rochester study, contributed to conceptualizing the analysis, participated in review of medical charts to define epilepsy variables and characterize patient deaths, and participated in revising the manuscript; Dr Geerts is 1 of the lead authors from the Dutch study, provided follow-up time information and information about causes of death, and participated in revision of the manuscript; Dr Callenbach is 1 of the lead authors from the Dutch study, provided information about the study and causes of death, and participated in revision of the manuscript; Dr Arts is 1 of the senior investigators of the Dutch study, provided review of causes of death, and participated in revision the manuscript; Ms Rios is the project coordinator for the Connecticut study, developed and executed the approaches for ascertaining death and causes of death, and participated in revising the manuscript; Dr P.R. Camfield is a co-principal investigator for the Nova Scotia study, provided additional information about the Nova Scotia study, reviewed causes of death, and participated in revising the manuscript; and Dr C.S Camfield is a co-principal investigator for the Nova Scotia study, provided additional information about the Nova Scotia study, critiqued the approach, and participated in revising the manuscript. All authors read and approved the submitted version.

(Continued on last page) 
Mortality rates in people with epilepsy are 2 to 4 times higher overall ${ }^{1-4}$ and 5 to 10 times higher in pediatric epilepsy. ${ }^{5-9}$ This increased risk occurs for several reasons: (1) lethal neurometabolic conditions that present with epilepsy; (2) systemic complications associated with neurodisability; (3) indirect factors resulting in higher mortality (eg, suicide); and (4) deaths shown or presumed to be directly due to the occurrence of a seizure. This last group includes sudden unexpected death in epilepsy (SUDEP), which has been the center of an international awareness campaign ${ }^{10}$ and many conferences, as well as the focus of several grant initiatives. Although increasing evidence is clarifying the sequence of events leading to SUDEP, many of which may have implications for prevention, there is still a reticence among neurologists to raise the subject of SUDEP with patients and families. A summary of the National Institutes of Neurologic Disorders and Stroke conference on SUDEP highlighted the importance of conveying information to families and patients about the risk of death in general and SUDEP in particular. ${ }^{11}$ Concerns were expressed that these discussions might cause anxiety or depression and that there is a need to distinguish between "low" risk and "no" risk. Further research was suggested to determine how best to provide information about SUDEP and how to overcome the reluctance of health professionals to present this information. This reluctance stands in sharp contrast to the situation in pediatrics, where pediatricians are trained and provide professional support in discussing these risks with parents beginning with the risk of sudden infant death syndrome (SIDS). ${ }^{12}$

One barrier in discussing SUDEP or seizure-related death is the paucity of data on which to base an accurate risk estimate, particularly in children and most especially at the time of initial diagnosis when the topic might reasonably first be raised. This lack of data exists in part because the risk is statistically very low and thus hard to determine in a single study. To address this knowledge gap, we pooled data from 4 large pediatric cohorts to obtain direct estimates of the mortality risk overall and from specific causes of mortality, particularly seizure related and SUDEP.

\section{METHODS}

The authors of 4 published pediatric cohort studies combined data regarding mortality. ${ }^{5-9}$ Methods for each study are outlined in Table 1. For 1 study, results are updated here from an earlier report based on an additional 8 years of follow-up. ${ }^{5}$
Deaths were ascertained systematically within each study. Methods included report of parents to study staff during scheduled follow-up calls5; report of treating physicians to study staff5,6,8; review of national death indices, health registries, and other administrative databases depending on the study ${ }^{5-8}$; and an active populationbased surveillance program. ${ }^{9}$ Epilepsy in association with lethal neurometabolic or neurodegenerative conditions was explicitly excluded from 1 study. ${ }^{7}$ To be consistent, children with such conditions were excluded from the other 3 studies for these analyses. Epilepsy presentation was considered "complicated" if there was a known structural brain lesion, significant intellectual disability, or abnormal result on neurologic examination; it was considered "uncomplicated" if these factors were absent.5,6,8,9 Children with autism generally had intellectual disability and were thus included in the complicated group. For 1 study, the distinction was based solely on the absence or presence of cognitive or neurologic disability. ${ }^{?}$ This information was extracted from the medical records as recorded by the child's treating neurologist. In 1 study, research MRIs and neurocognitive testing were performed in more than one-half of the cohort, ${ }^{5}$ and the results were used to

TABLE 1 Description of 4 Studies

\begin{tabular}{|c|c|c|c|c|}
\hline Variable & Nova Scotia ${ }^{7}$ & Netherlands ${ }^{6,8}$ & Connecticut $^{5}$ & Rochester $^{9}$ \\
\hline Years of recruitment & 1977-1985 & 1988-1992 & $1993-1997$ & 1980-2009 \\
\hline $\begin{array}{l}\text { Methods and patient } \\
\text { source }\end{array}$ & Prospective, population based & Prospective, regional & Prospective, community based & Retrospective, population based \\
\hline Inclusion criteria & $\begin{array}{l}\text { Newly diagnosed epilepsy; } \geq 2 \\
\text { unprovoked seizures } \\
\text { Evidence of progressive neurologic } \\
\text { disease was grounds for exclusion }\end{array}$ & $\begin{array}{l}\text { Newly diagnosed epilepsy; } \\
\geq 2 \text { unprovoked seizures }\end{array}$ & $\begin{array}{l}\text { Newly diagnosed epilepsy; } \\
\geq 2 \text { unprovoked seizures }\end{array}$ & $\begin{array}{l}\text { Newly diagnosed epilepsy; } \geq 2 \\
\text { unprovoked seizures or single } \\
\text { seizure with brain injury and } \\
\text { treatment initiated }\end{array}$ \\
\hline Age at onset & $\begin{array}{l}1 \mathrm{mo}-16 \mathrm{y} \\
\text { Mean } \pm \text { SD: } 6.2 \pm 4.5 \mathrm{y}\end{array}$ & $\begin{array}{l}1 \mathrm{mo}-16 \mathrm{y} \\
\text { Mean } \pm \text { SD: } 5.6 \pm 4.1 \mathrm{y}\end{array}$ & $\begin{array}{l}1 \mathrm{mo}-16 \mathrm{y} \\
\text { Mean } \pm \text { SD: } 5.8 \pm 4.0 \mathrm{y}\end{array}$ & $\begin{array}{l}1 \mathrm{mo}-17 \mathrm{y} \\
\text { Mean } \pm \text { SD: } 6.9 \pm 5.1 \mathrm{y}\end{array}$ \\
\hline $\begin{array}{l}\text { Age at time of } \\
\text { analysis in } \\
\text { survivors }\end{array}$ & Mean: 19.2 y & $\begin{array}{l}5.3-33.5 \text { y } \\
\text { Mean } \pm \text { SD: } 20.7 \pm 4.7 \text { y }\end{array}$ & $\begin{array}{l}14.5-35.0 \text { y } \\
\text { Mean } \pm \text { SD: } 23.3 \pm 4.3 \text { y }\end{array}$ & $\begin{array}{l}0.2-45.4 \text { y } \\
\text { Mean } \pm \text { SD: } 16.7 \pm 9 y\end{array}$ \\
\hline Age at death & $\begin{array}{l}0.5-30 y \\
\text { Mean } \pm \text { SD: } 12.0 \pm 7.3 \text { y }\end{array}$ & $\begin{array}{l}2.1-26.9 \text { y } \\
\text { Mean } \pm \text { SD: } 11.8 \pm 7.5 \text { y }\end{array}$ & $\begin{array}{l}1.8-28.7 \text { y } \\
\text { Mean } \pm \text { SD: } 11.2 \pm 8.8 \text { y }\end{array}$ & $\begin{array}{l}0.2-21.7 \text { y } \\
\text { Mean } \pm \text { SD: } 8.2 \pm 6.5 \text { y }\end{array}$ \\
\hline $\begin{array}{l}\text { Ascertainment of } \\
\text { deaths }\end{array}$ & $\begin{array}{l}\text { Provincial health registry and other } \\
\text { clinical sources }\end{array}$ & $\begin{array}{l}\text { Physician report to study, } \\
\text { national health records }\end{array}$ & $\begin{array}{l}\text { Family report to study, Social } \\
\text { Security Death Index }\end{array}$ & $\begin{array}{l}\text { Rochester Epidemiology Project } \\
\text { surveillance system }\end{array}$ \\
\hline
\end{tabular}


supplement clinical assessment. Person-years (PY) of follow-up were calculated for each patient as the time from study entry (diagnosis) to either death or, for survivors, date of last contact (Table 1).

All studies obtained copies of death certificates and, if performed, copies of autopsy reports. In some instances, eye witness accounts or emergency department or in-patient reports from terminal visits or hospitalizations were available and contributed to assignment of cause of death. Information about cause of death was compiled from death certificates, autopsy reports, and other medical records. Collaborating investigators reviewed the information, and a consensus was reached on how to best categorize each death.

Causes of death were grouped as SUDEP, other seizure related, other natural, and nonnatural (Table 2). In the absence of any information, the cause of death was characterized as unknown. SUDEP was further categorized into definite, probable, and possible SUDEP according to recent recommendations. ${ }^{13}$ In children with significant neurologic compromise, we considered an otherwise unexplained sudden death attributed to cardiac or cardiopulmonary arrest to be possible (not probable) SUDEP in the absence of an autopsy report that definitively excluded infections or other sources of airway compromise.

Death rates with 95\% confidence intervals (Cls) are reported as number per 100000 PY and were calculated by using standard techniques. ${ }^{14}$ Poisson regression was performed in SAS Proc Genmod (SAS version 9.2, SAS Institute, Inc, Cary, NC) to test for differences between studies and between complicated and uncomplicated epilepsy. We performed sensitivity analyses to examine the impact of the following: (1) counting possible SUDEP as seizure related; and (2) counting unknown cause as being seizure related or even SUDEP. For

TABLE 2 Definitions of Causes of Death

\begin{tabular}{|c|c|}
\hline SUDEP & $\begin{array}{l}\text { Sudden unexpected death in someone with epilepsy occurring in } \\
\text { benign circumstances for which no specific cause can be } \\
\text { identified. Level of certainty regardingthe designation of SUDEP } \\
\text { was determined with reference to the unified definition. }{ }^{13}\end{array}$ \\
\hline Definite & $\begin{array}{l}\text { Sudden unexpected witnessed or unwitnessed nontraumatic, } \\
\text { nondrowning death occurring in benign circumstances in } \\
\text { someone with epilepsy with or without evidence of a seizure in } \\
\text { which a postmortem examination does not reveal a cause of death. }\end{array}$ \\
\hline Probable & $\begin{array}{l}\text { Sudden unexpected witnessed or unwitnessed nontraumatic, } \\
\text { nondrowning death occurring in benign circumstances in } \\
\text { someone with epilepsy with or without evidence of a seizure } \\
\text { having occurred. No postmortem examination is performed or } \\
\text { results are unavailable. }\end{array}$ \\
\hline Possible & $\begin{array}{l}\text { A competing cause of death is present. Complications from severe } \\
\text { neurodevelopmental disability was considered a potential } \\
\text { competing cause of death in the absence of postmortem results. }\end{array}$ \\
\hline Seizure related, not SUDEP & $\begin{array}{l}\text { Any death that resulted from documented complications of a seizure } \\
\text { (e.g., aspiration during seizure), iatrogenic complications as the } \\
\text { result of treating acute seizures, or status epilepticus. }\end{array}$ \\
\hline Other natural & $\begin{array}{l}\text { Any death not attributable to a seizure or SUDEP and that could } \\
\text { specifically be attributed to an acute or chronic medical } \\
\text { condition. These could include conditions related to the } \\
\text { epilepsy (e.g., brain tumors), consequences of } \\
\text { neurodevelopmental impairments (aspiration pneumonia not } \\
\text { due directly to a seizure), infections, or other conditions (e.g., } \\
\text { cancer). Complication of treatment of a medical condition (e.g., } \\
\text { shunt malfunction) are considered in this category. }\end{array}$ \\
\hline Nonnatural causes & Any death attributable to homicide, suicide, or accidental death. \\
\hline Unknown & $\begin{array}{l}\text { Inadequate information available to make an attribution of the } \\
\text { specific cause of death or to group it into the scheme above }\end{array}$ \\
\hline
\end{tabular}

approximate comparisons, death rates in the first 3 decades of life from the 3 countries in which the studies were performed were obtained from vital statistics registries in each country. ${ }^{15-18}$ All procedures were approved by the ethics committees at all participating institutions. The Connecticut, Dutch, and Canadian studies obtained written informed consent for participation in the original studies. The Rochester Epidemiology Project functions under a community consent protocol.

\section{RESULTS}

The 3 studies included 2239 patients with childhood-onset epilepsy (onset $<16$ years of age $\mathrm{e}^{5-8}$ or $\leq 17$ years of age ${ }^{9}$ ). Ten children with lethal metabolic conditions (2, Menkes kinky hair disease; 4, neuronal ceroid lipofuscinoses; 1, Zellwegger syndrome; 2, mitochondrial disorders; 1, NiemannPick disease) were excluded from further consideration.
The remaining 2229 subjects were followed for a total of $30284 \mathrm{PY}$, and 69 deaths occurred (14-26 per study). The crude death rate per 100000 PY for all subjects combined was 228 (95\% Cl: 174-282). Point estimates of the crude rates varied somewhat among the 4 studies, but their Cls overlap (Table 3). A formal test of these differences indicated that they were not overall statistically significant. Within complicated and uncomplicated groups, these differences were greatly reduced. Data adequately fit assumptions for a Poisson distribution.

The death rate in the complicated group (743 [95\% Cl: 557-930]) was substantially higher than in the uncomplicated group (36 [95\% Cl: 11-61]) $(P<.0001)$.

\section{Causes of Death}

Ten deaths were attributed to SUDEP (5 definite with autopsy confirmation, 3 probable, and 2 possible). Three seizurerelated deaths occurred (1 status epilepticus, 1 iatrogenic complications 
TABLE 3 Mortality Figures Overall and for Complicated and Uncomplicated Epilepsy Presentations

\begin{tabular}{|c|c|c|c|c|c|}
\hline Study & Nova Scotia $^{7}$ & Netherlands ${ }^{6,8}$ & Connecticut ${ }^{5}$ & Rochester $^{9}$ & Total \\
\hline$N\left(n\right.$ subsequently excluded $\left.{ }^{\mathrm{a}}\right)$ & 686 & $472(3)$ & $613(5)$ & $468(2)$ & $2239(10)$ \\
\hline PY & 8918 & 6763 & 10047 & 4556 & 30284 \\
\hline Average follow-up (y) & 13.0 & 14.4 & 16.5 & 9.8 & 13.6 \\
\hline No. of deaths & 26 & 15 & 14 & 14 & 69 \\
\hline Crude death rate/100 $000 \mathrm{PY}(95 \% \mathrm{Cl})$ & $292(179-404)$ & $222(110-334)$ & 139 (66 212) & $307(146-468)$ & $228(174-282)$ \\
\hline Complicated & $n=173$ & $n=136$ & $n=149$ & $n=163$ & $n=621$ \\
\hline PY & 2249 & 1877 & 2381 & 1700 & 8207 \\
\hline Deaths & 23 & 14 & 11 & 13 & 61 \\
\hline Crude death rate $(95 \% \mathrm{Cl})$ & $1023(605-1441)$ & $745(355,1137)$ & $462(189-735)$ & $765(349-1180)$ & $743(567-930)$ \\
\hline Uncomplicated & $n=513$ & $n=333$ & $n=459$ & $n=303$ & $n=1608$ \\
\hline PY & 6669 & 4886 & 7665 & 2857 & 22077 \\
\hline Deaths & 3 & 1 & 3 & 1 & 8 \\
\hline Crude death rate $(95 \% \mathrm{Cl})$ & $45(0-96)$ & $21(0.61)$ & $39(0-83)$ & $35(0-104)$ & $36(11-61)$ \\
\hline
\end{tabular}

$\mathrm{Cl}$, confidence interval.

a Number with neurometabolic diseases who are reported in the tallies for these cohorts in the literature but who have been subsequently excluded from further analyses.

from treatment of status epilepticus, and 1 aspiration during a seizure). Other natural causes accounted for 48 deaths (pneumonia $[n=35]$, sepsis $[n=3$ ], ventriculoperitoneal shunt malfunction $[n=3]$, tracheotomy malfunction $[n=1]$, pulmonary embolism [ $n=1]$, cerebral hemorrhage $[n=2]$, cancer $[n=2]$, and cardiomyopathy $[n=$ 1]). Five deaths were due to nonnatural causes (2 nonseizure-related accidents, 2 suicides, and 1 homicide). No information was available regarding cause of death for the remaining 3 individuals.

Death rates according to types of cause were calculated overall and for complicated and uncomplicated presentations (Table 4). For potentially seizure-related deaths, we calculated rates for SUDEP $(n=10)$, definite and probable SUDEP $(n=8)$, all seizure-related death $(n=13$
[10 SUDEP and 3 other]), and seizurerelated deaths plus unknown $(n=16$ [SUDEP, other seizure-related, and unknown]). All causes of death were substantially higher in the complicated group compared with the uncomplicated group. The rate of seizurerelated deaths in the complicated group (122 per 100000 PY) was multiples of the total population death rates in the first 3 decades of life and higher than SIDS rates in developed countries (Table 5). The comparable figure for the uncomplicated group (14 per $100000 \mathrm{PY}$ ) was in the same range as or slightly higher than the single leading causes of death for young people in the population (depending on the country), at the low end of the range for SIDS in developed countries, and higher than 1 estimate of sudden death in the 1 - to 30-year-olds.

TABLE 4 Estimated Mortality Rates for All Study Participants and for Uncomplicated and Complicated Epilepsy Presentations for Total Mortality and Cause-Specific Mortality in the 4 Combined Cohorts

\begin{tabular}{|c|c|c|c|}
\hline Mortality & Overall & Complicated & Uncomplicated \\
\hline Overall mortality & $228(174-282)$ & $743(557-930)$ & $36(11-61)$ \\
\hline SUDEP & $33(13-53)$ & $98(30-165)$ & $9(0-22)$ \\
\hline Definite and probable SUDEP & $26(8-45)$ & $73(15-132)$ & $9(0-22)$ \\
\hline Any seizure-related death & $43(20-66)$ & $122(46-197)$ & $14(0-29)$ \\
\hline Any seizure-related death and unknown ${ }^{a}$ & $53(27-79)$ & $146(63-229)$ & $18(0-36)$ \\
\hline SUDEP and unknown ${ }^{\mathrm{a}}$ & $43(20-66)$ & $122(46-197)$ & $14(0-29)$ \\
\hline Other natural causes & $159(114-203)$ & $561(399-722)$ & $9(0-22)$ \\
\hline
\end{tabular}

All estimates are reported per 100000 PY with 95\% Cls.

a Added to seizure-related deaths to determine the impact of the 3 unknown cases on seizure-related death. The difference between figures calculated with and without the unknown deaths reflects the potential error in estimating this figure due to the missing information for these 3 individuals.

\section{Patient Profiles Associated With Mortality}

Deaths occurred on average $7.5( \pm 4.9)$ years after diagnosis (Table 6 ). In the complicated group, there was a moderate trend suggesting that older onset was associated with a longer time to death (Fig 1).

Average age at death was 11.6 years and was similar across most causes of death. Male and female subjects were approximately equally represented across cause of death categories. Given the small numbers involved, formal tests were not conducted. Data are presented for descriptive purposes only.

Most of the deaths ( $n=61$ [88\%]) occurred in participants with complicated presentations, and almost all of these individuals had mild $(n=5)$ or more severe $(n=51)$ cognitive impairment. Drug resistance (57\%), lack of seizure freedom in the past year (74\%), and a history of convulsive seizures (68\%) and of status epilepticus (48\%) were all more common than reported for these cohorts in previous publications. ${ }^{5-9}$ No seizure-related deaths occurred in children with the generally pharmacoresponsive and often self-limited syndromes such as childhood absence epilepsy or benign rolandic epilepsy. Two accidental deaths occurred; neither was seizure related. 


\section{DISCUSSION}

Compared with death rates for 1 - to 29 year-olds in the United States, Canada, and the Netherlands, the overall death rates in young people followed from their initial diagnosis of childhoodonset epilepsy were substantially elevated. Most of the excess risk occurred in association with complicated epilepsy presentations, particularly with neurologic and intellectual disability. The crude mortality rate in this group (743 per 100 000) exceeded recent reports for infant mortality rates in the same countries from which the cohorts came (Table 5). Most of the deaths were secondary to infections

TABLE 5 Mortality Rates by Age and for Specific Causes in the United States, Canada, and the Netherlands

\begin{tabular}{|c|c|c|c|}
\hline Mortality Age Group or Cause & United States $^{15}$ & Canada $^{16-17}$ & The Netherlands ${ }^{18}$ \\
\hline Infant & 630 & 510 & 439 \\
\hline SIDS & 57 & 35 & 9 \\
\hline \multicolumn{4}{|l|}{ 1- to 29-year-olds ${ }^{a}$} \\
\hline Overall & 55 & 34 & 26 \\
\hline Accidental & 24.6 & 14.2 & 7.0 \\
\hline Homicide & 7.5 & 2.0 & 0.9 \\
\hline Suicide & 6.8 & 6.9 & 3.0 \\
\hline Cancers & 4.3 & 4.5 & 3.9 \\
\hline Heart/circulatory & 3.2 & 2.5 & 1.9 \\
\hline
\end{tabular}

Rates are given per 100000 per year.

a Weighted average based on age-specific brackets and complications from underlying neurologic disability, which by itself confers a substantial mortality risk. ${ }^{19-25}$ Prevention of such deaths, when possible, likely lies in the arena of longterm supportive care and infection control, not seizure management per se. Inclusion of 10 children with diagnosed neurometabolic syndromes with a known lethal course yielded a higher death rate overall (261 [95\% Cl: 203-318]), particularly in the complicated group (861 [95\% Cl: 661-1062]). As with the neurodisability group, prevention of deaths associated with these diseases has little to do with seizure management. Comparable to reports from other researchers, 2,22,26 the death rate in the uncomplicated epilepsy group did not seem substantially greater than expected for the general population.

TABLE 6 Characteristics of Young People who Died (Overall and Grouped According to Cause of Death)

\begin{tabular}{|c|c|c|c|c|c|}
\hline Characteristic & $\begin{array}{l}\text { Overall } \\
\left(N=69^{\mathrm{a}}\right)\end{array}$ & $\begin{array}{l}\text { SUDEP } \\
(n=10)\end{array}$ & $\begin{array}{l}\text { Other Seizure Related } \\
\qquad(n=3)\end{array}$ & $\begin{array}{l}\text { Other Natural } \\
\qquad(n=48)\end{array}$ & $\begin{array}{l}\text { Nonnatural } \\
\quad(n=5)\end{array}$ \\
\hline Median age at onset & $2.0 \mathrm{y}$ & $2.7 \mathrm{y}$ & $4.6 \mathrm{y}$ & $1.3 \mathrm{y}$ & $12.0 y$ \\
\hline IQR (minimum, maximum) & 6 mo-7.0 y (1 mo- 15.7 y) & $1.3-11.8$ y (1 mo-12.3 y) & (8 mo-9.8 y) & $0.3-3.7$ y (1 mo-12y) & $11.4-14.0$ y $(3.4-15.3$ y) \\
\hline Median age at death & $11.0 \mathrm{y}$ & 13.7 y & $7.8 \mathrm{y}$ & 8.3 y & 18.2 y \\
\hline IQR (minimum, maximum) & $5-17$ y $(7 \mathrm{mo}-30 \mathrm{y})$ & $5.5-20$ y $(2.0-27.9$ y) & $(5.0-15.8 \mathrm{y})$ & $4.0-13.7$ y (7 mo-28.6 y) & $18.0-19.2$ y $(13.9-30.0$ y) \\
\hline Median time to death & $7.0 \mathrm{y}$ & $9.2 y$ & $6.3 \mathrm{y}$ & $5.3 \mathrm{y}$ & $8.3 \mathrm{y}$ \\
\hline IQR (minimum, maximum) & $3.2-11.7$ y ( $5 \mathrm{mo}-20.2$ y) & $3.2-12.8$ y (5 mo- 15.9 y) & $1.3-6.9$ y & $2.8-11.6$ y (8 mo-20.2 y) & $7.5-10.4$ y $(4.0-14.5$ y) \\
\hline \multicolumn{6}{|l|}{ Gender, $n(\%)$} \\
\hline Male & $37(54)$ & $5(50)$ & $2(67)$ & $23(48)$ & $4(80)$ \\
\hline Female & $32(46)$ & $5(10)$ & $1(33)$ & $45(52)$ & $1(20)$ \\
\hline \multicolumn{6}{|l|}{ Presentation of epilepsy, $n$ (\%) } \\
\hline Complicated & $61(88)$ & $8(80)$ & $2(67)$ & $46(96)$ & $3(60)$ \\
\hline Uncomplicated & $8(12)$ & $2(20)$ & $1(33)$ & $2(4)$ & $2(20)$ \\
\hline \multicolumn{6}{|l|}{ Cognitive level, $n$ (\%) } \\
\hline Normal & $13(19)$ & $3(30)$ & $1(33)$ & $4(8)$ & $4(80)$ \\
\hline Mildly impaired & $5(7)$ & $3(30)$ & $1(33)$ & $1(2)$ & $0(0)$ \\
\hline Moderately/severely impaired & $51(74)$ & $4(40)$ & $1(33)$ & $43(90)$ & $1(20)$ \\
\hline \multicolumn{6}{|l|}{ Type of epilepsy, $n$} \\
\hline Nonsyndromic-focal & 33 & 6 & 3 & 19 & 4 \\
\hline $\begin{array}{l}\text { Nonsyndromic-generalized, } \\
\text { mixed }\end{array}$ & 20 & 1 & 0 & 17 & 0 \\
\hline $\begin{array}{l}\text { West, LGS, Ohtahara, Dravet } \\
\text { syndromes }\end{array}$ & 13 & 3 & 0 & 10 & 0 \\
\hline Other & 3 & 0 & 0 & 2 & 1 \\
\hline Drug resistance, $n$ (\%) & $39(57)$ & $6(60)$ & $3(100)$ & $27(56)$ & $3(60)$ \\
\hline Epilepsy surgery, $n$ (\%) & $3(4)$ & $2(20)$ & $0(0)$ & $1(2)$ & $0(0)$ \\
\hline Seizure in last year, $n(\%)$ & $51(74)$ & $9(90)$ & $3(100)$ & $34(71)$ & $3(60)$ \\
\hline Convulsions, $n(\%)$ & $47(68)$ & $9(50)$ & $3(100)$ & $31(65)$ & $3(60)$ \\
\hline Status epilepticus, $n$ (\%) & $33(48)$ & $5(50)$ & $3(100)$ & $24(50)$ & $1(20)$ \\
\hline
\end{tabular}

A version of this table with Cls is available online as Supplemental Information. For seizure control, an indicator for $<1$ versus $\geq 1$ year seizure-free at time of death or at last contact was adopted because this factor could be accurately applied in all patients given the variability in coding of information across studies. Pharmacoresistance was defined fairly consistently across the studies with only minor variations. All studies required failure of at least 2 or 3 medications to meet the criteria for pharmacoresistance. IQR, interquartile range; LGS, Lennox-Gastaut syndrome.

a Three subjects with unknown causes are not included beyond the overall summary information. 


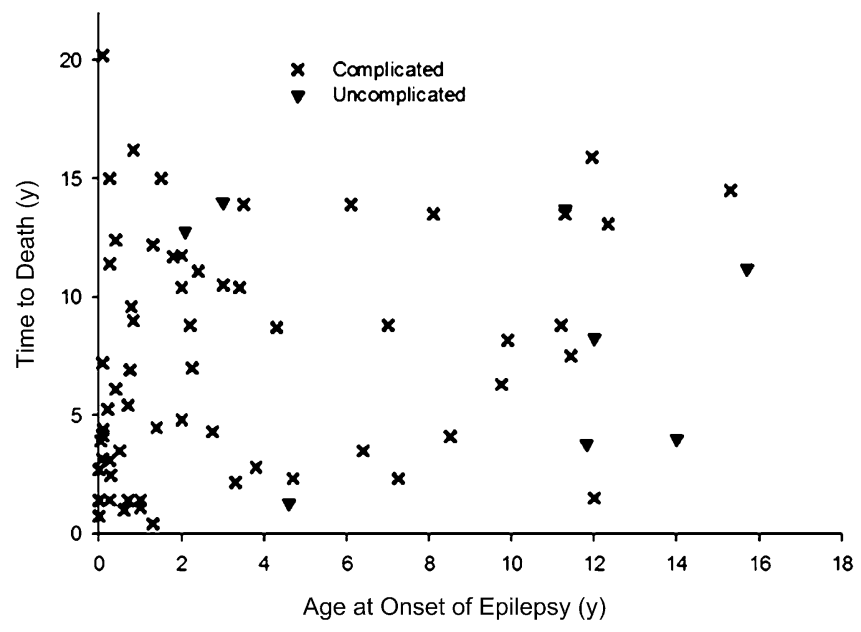

FIGURE 1

Association between age at onset of epilepsy and time to death in complicated and uncomplicated groups. The correlation between age at onset and years to death was $0.25(P=.05)$ in the complicated group and $-0.20(P=.63)$ in the uncomplicated group.

Sudden death is of particular concern for people with epilepsy and their families. ${ }^{10}$ In young adults (aged 20-40 years), the rate of sudden death in people with epilepsy is estimated to be 24 times that seen in the general population. ${ }^{27}$ The crude death rate from SUDEP alone in our combined series (33 per 100000 PY overall and 26 per 100000 PY for definite/probable SUDEP) is similar to the total population death rate in the first 2 decades of life (excluding infancy) (Table 6). In participants with complicated presentations, however, the SUDEP rate was 2 to 3 times the overall death rates seen in the general population. In fact, others have found a preponderance of SUDEP in association with complicated epilepsy. ${ }^{28-31}$

In young people with uncomplicated epilepsy, the death rates from SUDEP (9 per $100000 \mathrm{PY}$ ) and all seizure-related deaths (14 per 100000 PY) are comparable to the leading cause of death (accidents) and higher than other common causes of death, including homicide, suicide, cancer, and heart disease (Table 5). Our estimated SUDEP and seizure-related death rates are in the same range as SIDS death rates in developed countries (9 per 100000 [Japan] to 80 per 100000 [New Zealand]).32
Our point estimates, even for uncomplicated epilepsy, are greater than the rate for all sudden deaths reported in the Netherlands in 1- to 30-year-olds (2.26 per 100000 PY).

SUDEP risk is age related and is higher in adults, both in adult-onset epilepsy ${ }^{30}$ and in adults with childhood-onset epilepsy. ${ }^{33}$ No firm data are available, but anecdotal reports $^{10}$ and identified risk factors ${ }^{34}$ suggest that the transition time for adolescents and young adults, who may not fully understand the importance of good sleep and nutrition patterns, avoidance of excess alcohol and use of drugs, and adherence to prescribed treatment for preventing seizures, may pose some risks that could be modified. Transition from pediatric to adult care is complicated and particularly so in children with chronic neurologic conditions. ${ }^{35}$

Somewhat less appreciated is that SUDEP also occurs in infants and young children. A recent survey of parents whose children had Dravet syndrome reported a series of 31 deaths, 19 of which were attributed to SUDEP. The majority of the children were aged $<5$ years at the time of their deaths. ${ }^{36}$ Current thinking suggests there is a spectrum of sudden death in the very young beginning with
SIDS, of which SUDEP may be a part and which involves a variety of mechanisms including brainstem serotonergic dysfunction and heart channelopathies. ${ }^{32,37-39}$ Whether mechanisms involved in SUDEP in very young children differ from those in older individuals is under investigation.

The absence of definite seizure-related accidental deaths was encouraging. Potentially, the 3 deaths for which the causes were unknown could have been due to seizure-related accidents; however, including these 3 deaths still places an upper limit on such deaths in our combined cohorts. The low or absent risks we observed in no way indicate that the potential risks are not real. We speculate that common sense measures to prevent seizure-related accidents and accidental deaths in young persons may be having an impact.

The suicide rate was also comparable to that in the general population. Our estimate could be higher if any of the deaths with unknown causes were due to suicide. Relationship to medication use was not available in all studies; however, as reviewed elsewhere, the risks associated with uncontrolled seizures far outweigh the risk of suicide and any potential increased risk of suicide associated with medication use, a risk that has largely been disproven. 40 Our study has several advantages. We assembled perhaps the largest series of population-representative pediatric epilepsy patients followed from initial diagnosis for $\geq 10$ years. All studies independently took very similar approaches to defining entry criteria and targeted the same age-at-onset range. All studies had systematic approaches to determine that a death had occurred and obtained death certificates and when available, autopsy reports. Hospital records and eye witness accounts were also reviewed when available. We used the recent recommendations on SUDEP definitions and determined 
the level of certainty regarding that designation. ${ }^{13}$

There are inevitable weaknesses. Studies were performed in different populations during largely nonoverlapping time periods. We were not able to combine data at an individual level because files were no longer available for 1 study. We could not make precise comparisons with population death rates because studies were performed in different countries and over different time periods. However, such comparisons are always approximate. We present them to place our mortality findings in a larger context.

Unlike SIDS, for which there has been a major public health campaign aimed at providers and parents and advanced through the American Academy of Pediatrics $^{12}$ and other organizations, discussion of SUDEP still seems to encounter a certain reluctance on the part of neurologic care providers. ${ }^{11}$ Parents, however, generally do want to be informed of these risks, ${ }^{41}$ and

\section{REFERENCES}

1. Hauser WA, Annegers JF, Elveback LR. Mortality in patients with epilepsy. Epilepsia. 1980;21 (4):399-412

2. Lhatoo SD, Johnson AL, Goodridge DM, MacDonald BK, Sander JW, Shorvon SD. Mortality in epilepsy in the first 11 to 14 years after diagnosis: multivariate analysis of a long-term, prospective, population-based cohort. Ann Neurol. 2001;49(3):336-344

3. Loiseau J, Picot MC, Loiseau P. Short-term mortality after a first epileptic seizure: a population-based study. Epilepsia. 1999; 40(10):1388-1392

4. Olafsson E, Hauser WA, Gudmundsson G. Long-term survival of people with unprovoked seizures: a population-based study. Epilepsia. 1998;39(1):89-92

5. Berg AT, Shinnar S, Testa FM, Levy SR, Smith SN, Beckerman B. Mortality in childhood-onset epilepsy. Arch Pediatr Adolesc Med. 2004;158(12):1147-1152

6. Callenbach PM, Westendorp RG, Geerts AT, et al. Mortality risk in children with epilepsy: parents who have lost children wish they had been offered such information. ${ }^{10}$ Although this reluctance and unease among neurologists will surely change, ${ }^{42}$ it seems that pediatricians who have overcome the barriers of discussing such risks with their families and young patients might be well positioned, if provided with reasonable information about SUDEP, to broach these topics and to address parents' concerns. Ways of preventing SUDEP are unclear and not as advanced as with SIDS. The main risk factor for SUDEP is lack of seizure control, which highlights the importance of adherence to recommended medication schedules. ${ }^{43,44}$ Children with seizures during sleep may also be at increased risk depending on their epilepsy and seizure type, and families may benefit from discussion about this particular concern. Reasonable supervision and precautions may also mitigate some of the risk. ${ }^{45}$ These issues can be emphasized with parents of young children with epilepsy as well as with adolescents acquiring greater autonomy and transitioning to adult care. ${ }^{35}$

\section{CONCLUSIONS}

Most mortality in young people with epilepsy is secondary to factors associated with neurodisability. Sudden and other seizure-related death does occur at rates higher than in the general population, although most of the risk occurs in association with complicated epilepsy. Demystifying the risk by measuring it and placing it in the context of other risks of childhood death faced by all parents may facilitate discussion of seizure-related death. Pediatricians may benefit those families who have a child with epilepsy by discussing these issues frankly. Generally, they can offer reassurance regarding the actual magnitude of the risk. Providing families with such information as well as an understanding of the importance of medication adherence and other common sense measures is a role appropriate for primary care providers. the Dutch Study of Epilepsy in Childhood. Pediatrics. 2001;107(6):1259-1263

7. Camfield CS, Camfield PR, Veugelers PJ. Death in children with epilepsy: a population-based study. Lancet. 2002;359(9321):1891-1895

8. Geerts AT, Arts WF, Stroink H, et al. Course and outcome of childhood epilepsy: a 15-year follow-up of the Dutch Study of Epilepsy in Childhood. Epilepsia. 2010;51(7):1189-1197

9. Nickels KC, Grossardt BR, Wirrell EC. Epilepsyrelated mortality is low in children: a 30-year population-based study in Olmsted County, MN. Epilepsia. 2012 Dec;53(12):2164-2171

10. Chapman D, Panelli R, Hanna J, Jeffs T, eds. Sudden Unexpected Death in Epilepsy: Continuing the Global Conversation. Victoria, Australia, Wantage, UK, Toronto, Canada: Epilepsy Australia Ltd, Epilepsy Bereaved, SUDEP Aware; 2011

11. Hirsch LJ, Donner EJ, So EL, et al. Abbreviated report of the NIH/NINDS workshop on sudden unexpected death in epilepsy. $\mathrm{Neu}$ rology. 2011;76(22):1932-1938
12. American Academy of Pediatrics Task Force on Sudden Infant Death Syndrome. The changing concept of sudden infant death syndrome: diagnostic coding shifts, controversies regarding the sleeping environment, and new variables to consider in reducing risk. Pediatrics. 2005;116(5):1245-1255

13. Nashef L, So EL, Ryvlin P, Tomson T. Unifying the definitions of sudden unexpected death in epilepsy. Epilepsia. 2012;53(2):227-233

14. Breslow NE, Day NE. The Design and Analysis of Cohort Studies. Lyons, France: IARC Press; 1987

15. Heron M. Deaths: Leading Causes for 2007. In: National Vital Statistics Reports: Centers for Disease Control and Prevention, National Center for Health Statistics, National Vital Statistics System; 2011:1-96

16. Statistics Canada. Leading Causes of Death, Canada, 2005, Males and Females Combined Available at: www.phac-aspc.gc.ca/ publicat/lcd-pcd97/pdf/lcd-pcd-t1-eng.pdf. Accessed June 13, 2012 
17. Gilbert NL, Fell DB, Joseph KS, et al. Temporal trends in sudden infant death syndrome in Canada from 1991 to 2005: contribution of changes in cause of death assignment practices and in maternal and infant characteristics. Paediatric and Perinatal Epidemiology. 2012;26:124-130

18. Population, households and population dynamics; from 1899 Centraal Bureau voor Statistiek. Available at: http://statline.cbs. $\mathrm{nl} /$ StatWeb/publication/?DM $=$ SLEN\&PA $=$ 37556eng\&D1 =3-8,53-60,64-69,75-120,147, $157,167,177,180,182-183,189-190 \& D 2=105 \&$ $L A=E N \& V W=T a s p x$. Accessed June 14, 2012

19. Ackers R, Besag FM, Hughes E, Squier W, Murray ML, Wong IC. Mortality rates and causes of death in children with epilepsy prescribed antiepileptic drugs: a retrospective cohort study using the UK General Practice Research Database. Drug Saf. 2011;34(5):403-413

20. Day SM, Wu YW, Strauss DJ, Shavelle RM, Reynolds RJ. Causes of death in remote symptomatic epilepsy. Neurology. 2005;65(2):216-222

21. Decouflé P, Autry A. Increased mortality in children and adolescents with developmental disabilities. Paediatr Perinat Epidemiol. 2002;16(4):375-382

22. Forsgren L, Edvinsson S0, Nyström L, Blomquist HK. Influence of epilepsy on mortality in mental retardation: an epidemiologic study. Epilepsia. 1996;37(10):956-963

23. Nesbitt V, Kirkpatrick M, Pearson G, Colver A, Forsyth R. Risk and causes of death in children with a seizure disorder. Dev Med Child Neurol. 2012;54(7):612-617

24. Plioplys AV. Survival rates of children with severe neurologic disabilities: a review. Semin Pediatr Neurol. 2003;10(2):120-129

25. Plioplys AV, Kasnicka I, Lewis S, Moller D. Survival rates among children with severe neurologic disabilities. South Med J. 1998; 91(2):161-172

26. Chin RF, Cumberland PM, Pujar SS, Peckham C, Ross EM, Scott RC. Outcomes of childhood epilepsy at age 33 years: a population-based birthcohort study. Epilepsia. 2011;52(8):1513-1521

27. Ficker DM, So EL, Shen WK, et al. Population-based study of the incidence of sudden unexplained death in epilepsy. Neurology. 1998;51(5):1270-1274

28. Donner EJ, Smith CR, Snead OC III. Sudden unexplained death in children with epilepsy. Neurology. 2001;57(3):430-434

29. Nashef L, Brown S. Epilepsy and sudden death. Lancet. 1996;348(9038):1324-1325

30. Walczak TS, Leppik IE, D'Amelio M, et al. Incidence and risk factors in sudden unexpected death in epilepsy: a prospective cohort study. Neurology. 2001;56(4):519-525

31. Weber P, Bubl R, Blauenstein U, Tillmann BU, Lütschg J. Sudden unexplained death in children with epilepsy: a cohort study with an eighteen-year follow-up. Acta Paediatr. 2005;94(5):564-567

32. Kinney HC, Thach BT. The sudden infant death syndrome. N Engl J Med. 2009;361(8):795-805

33. Sillanpää M, Shinnar S. Long-term mortality in childhood-onset epilepsy. $N$ Engl J Med. 2010;363(26):2522-2529

34. Tomson T, Nashef L, Ryvlin P. Sudden unexpected death in epilepsy: current knowledge and future directions. Lancet Neurol. 2008; (11):1021-1031

35. Camfield P, Camfield C. Transition to adult care for children with chronic neurological disorders. Ann Neurol. 2011;69(3):437-444

36. Skluzacek JV, Watts KP, Parsy 0, Wical B, Camfield P. Dravet syndrome and parent associations: the IDEA League experience with comorbid conditions, mortality, man- agement, adaptation, and grief. Epilepsia. 2011;52 (suppl 2):95-101

37. McGarvey CM, O'Regan M, Cryan J, et al. Sudden unexplained death in childhood (1-4 years) in Ireland: an epidemiological profile and comparison with SIDS. Arch Dis Child. 2012;97(8):692-697

38. Richerson GB. Serotonergic neurons as carbon dioxide sensors that maintain $\mathrm{pH}$ homeostasis Nat Rev Neurosci. 2004;5(6):449-461

39. Tester DJ, Ackerman MJ. Cardiomyopathic and channelopathic causes of sudden unexplained death in infants and children. Annu Rev Med. 2009;60:69-84

40. Hesdorffer DC, Berg AT, Kanner AM. An update on antiepileptic drugs and suicide: are there definitive answers yet? Epilepsy Curr. 2010;10(6):137-145

41. Gayatri NA, Morrall MC, Jain V, Kashyape P, Pysden K, Ferrie C. Parental and physician beliefs regarding the provision and content of written sudden unexpected death in epilepsy (SUDEP) information. Epilepsia. 2010;51(5):777-782

42. England MJ, Liverman CT, Schultz AM, Strawridge LM, eds. Epilepsy Across the Spectrum: Promoting Health and Understanding. Washington, DC: The National Academies Press; 2012

43. Langan Y, Nashef L, Sander JW. Case-control study of SUDEP. Neurology. 2005;64(7):1131-1133

44. Faught E, Duh MS, Weiner JR, Guérin A, Cunnington MC. Nonadherence to antiepileptic drugs and increased mortality: findings from the RANSOM Study. Neurology. 2008;71(20):1572-1578

45. Nashef L, Fish DR, Garner S, Sander JW Shorvon SD. Sudden death in epilepsy: a study of incidence in a young cohort with epilepsy and learning difficulty. Epilepsia 1995;36(12):1187-1194

(Continued from first page)

www.pediatrics.org/cgi/doi/10.1542/peds.2012-3998

doi:10.1542/peds.2012-3998

Accepted for publication Mar 21, 2013

This work was presented in preliminary form at the Partners Against Mortality in Epilepsy conference; June 22-24, 2012; Evanston, II. It was also presented at the American Epilepsy Society meeting; November 30-December 4, 2012; San Diego, CA.

The content is solely the responsibility of the authors and does not necessarily represent the official views of the National Institutes of Health.

Address correspondence to Anne T. Berg, PhD, Epilepsy Center, Ann \& Robert H. Lurie Children's Hospital of Chicago, 225 East Chicago Ave, Box 29, Chicago, IL 60611. E-mail: atberg@luriechildrens.org

PEDIATRICS (ISSN Numbers: Print, 0031-4005; Online, 1098-4275).

Copyright $(2013$ by the American Academy of Pediatrics

FINANCIAL DISCLOSURE: Dr Berg has received speaker honoraria and travel support from Bial and Medical University of South Carolina and travel support from the International League Against Epilepsy serves on advisory boards for Citizens United for Research in Epilepsy and Eisai; serves on the editorial boards of Epilepsy \& Behavior and Neurology; and is supported by funding from the National Institute of Neurological Disorders and Stroke (grant R37-NS31146) and the Pediatric Epilepsy Research Foundation. Dr Callenbach received an unrestricted research grant from UCB Pharma B.V. Drs Nickel and Wirrell were supported in this work by a Mayo Foundation CR20 Award. In addition, the research reported in this publication was supported by the National Institute on Aging of the National Institutes of Health under 